University of Nebraska - Lincoln

DigitalCommons@University of Nebraska - Lincoln

Food and Drug Administration Papers

U.S. Department of Health and Human Services

2018

Etiology of Teen Dating Violence among Adolescent Children of Alcoholics

Jennifer A. Livingston

University at Buffalo, livingst@ria.buffalo.edu

Rina D. Eiden

University at Buffalo, eiden@ria.buffalo.edu

Jared Lessard

Office of Planning, Research and Accreditation, gilgamesh80@gmail.com

Meghan Casey

University at Buffalo, mcasey@ria.buffalo.edu

James Henrie

Food and Drug Administration Center for Tobacco Products, henrie.james@gmail.com

See next page for additional authors

Follow this and additional works at: https://digitalcommons.unl.edu/usfda

Part of the Dietetics and Clinical Nutrition Commons, Health and Medical Administration Commons, Health Services Administration Commons, Pharmaceutical Preparations Commons, and the Pharmacy Administration, Policy and Regulation Commons

Livingston, Jennifer A.; Eiden, Rina D.; Lessard, Jared; Casey, Meghan; Henrie, James; and Leonard, Kenneth E., "Etiology of Teen Dating Violence among Adolescent Children of Alcoholics" (2018). Food and Drug Administration Papers. 46.

https://digitalcommons.unl.edu/usfda/46

This Article is brought to you for free and open access by the U.S. Department of Health and Human Services at DigitalCommons@University of Nebraska - Lincoln. It has been accepted for inclusion in Food and Drug Administration Papers by an authorized administrator of DigitalCommons@University of Nebraska - Lincoln. 


\section{Authors}

Jennifer A. Livingston, Rina D. Eiden, Jared Lessard, Meghan Casey, James Henrie, and Kenneth E. Leonard 


\title{
Etiology of Teen Dating Violence among Adolescent Children of Alcoholics
}

\author{
Jennifer A. Livingston ${ }^{1} \cdot$ Rina D. Eiden ${ }^{1} \cdot$ Jared Lessard $^{2} \cdot$ Meghan Casey $^{1}$ \\ James Henrie $^{3}$ - Kenneth E. Leonard ${ }^{1}$
}

Received: 21 June 2016 / Accepted: 26 July 2017 / Published online: 8 August 2017

(C) Springer Science+Business Media, LLC 2017

U.S. government works are not subject to copyright.

\begin{abstract}
Family processes in early life have been implicated in adolescent involvement in teen dating violence, yet the developmental pathways through which this occurs are not well understood. In this study, etiological pathways from parental psychopathology and marital conflict in infancy to involvement in dating violence in late adolescence were examined in a sample of children at high-risk due to parental alcohol problems. Families $(N=227)$ recruited when the child was 12 months of age were assessed at 12-, 24-, 36-months, kindergarten, 6th, 8th, and 12 th grades. Slightly more than half of the children were female (51\%) and the majority were of European American descent $(91 \%)$. Parental psychopathology in infancy was indirectly associated with teen dating violence in late
\end{abstract}

Jennifer A. Livingston

livingst@ria.buffalo.edu

Rina D. Eiden

eiden@ria.buffalo.edu

Jared Lessard

gilgamesh80@gmail.com

Meghan Casey

mcasey@ria.buffalo.edu

James Henrie

henrie.james@gmail.com

Kenneth E. Leonard

leonard@ria.buffalo.edu

1 Research Institute on Addictions, University at Buffalo, 1021 Main Street, Buffalo, NY 14203, USA

2 Office of Planning, Research and Accreditation, Saddleback College, 2800 Marguerite Parkway, Mission Viejo, CA 92692, USA

3 Food and Drug Administration Center for Tobacco Products, 10903 New Hampshire Avenue, Silver Spring, MD 20993, USA adolescence via low maternal warmth and self-regulation in early childhood, externalizing behavior from kindergarten to early adolescence, and sibling problems in middle childhood. Marital conflict was also indirectly associated with teen dating violence via child externalizing behavior. Maternal warmth and sensitivity in early childhood emerged as an important protective factor and was associated with reduced marital conflict and increased child self-regulation in the preschool years as well as increased parental monitoring in middle childhood and early adolescence. Family processes occurring in the preschool years and in middle childhood appear to be critical periods for creating conditions that contribute to dating violence risk in late adolescence. These findings underscore the need for early intervention and prevention with at-risk families.

Keywords Teen dating violence $\cdot$ Adolescence $\cdot$ Etiology $\cdot$ Parenting $\cdot$ Self-regulation $\cdot$ Aggression

\section{Introduction}

Disturbingly, approximately $30 \%$ of adolescents in the US experience psychological, physical or sexual aggression within their romantic relationships (see Offenhauer and Buchalter 2011). In the extreme, teen dating violence can result in serious injury or death. Less extreme, but still devastating consequences include depression, posttraumatic stress symptoms, substance use, re-victimization and increased risk of experiencing interpersonal violence in adult relationships (Exner-Cortens et al. 2013; Smith et al. 2003). Although several correlates and risk factors for teen dating violence have been identified, prevention efforts 
have been hampered by a lack of understanding of its etiology, especially from early childhood to adolescence. This is largely due to the dearth of longitudinal and developmental research focusing on teen dating violence, especially research with samples at high risk. The goal of this study was to examine these etiological pathways beginning in infancy using a sample of adolescents at high risk for involvement in teen dating violence due to parental alcohol problems and psychopathology.

\section{The Role of Parental Psychopathology in the Development of Aggression}

Parenting behavior plays a critical role in the development of aggression in both children and adolescents and has been implicated in teen dating violence (Jouriles et al. 2012; Makin-Byrd and Bierman 2013). Both parental behavior toward their children and parental behavior toward each other have implications for the continuity of aggression from childhood to adolescence (Fuller et al. 2003; Jouriles et al. 2012). Children of parents who suffer from substance abuse and other psychopathology may be at particularly high risk for involvement in dating violence due to the effects of parental psychopathology on the development and maintenance of childhood aggression.

There is a robust literature linking parental alcohol problems to the development of externalizing problem behaviors, including aggression, in their young children (Edwards et al. 2006; Loukas et al. 2001). Alcohol problems tend to be comorbid with other psychopathology such as depression and antisocial behavior in both partners and this psychopathology has been implicated in child externalizing behavior (see Eiden and Leonard 2000; Hutchinson et al. 2014). Direct associations between parental psychopathology and child externalizing behavior may reflect potential genetic associations (Villafuerte et al. 2012), but may also set the stage for socialization experiences that interfere with normative declines in aggression from preschool to early school age. For example, Fuller et al. (2003) found that fathers' antisocial behavior predicted their sons' preschool aggression both directly and indirectly via paternal alcohol use disorder and parent-to-parent aggression. Psychopathology in one or both parents interferes with their ability to relate to each other and to their children. As a result, these families tend to experience greater marital conflict and exhibit low quality parenting behaviors (Eiden et al. 1999; Finger et al. 2010). Adolescents living in such a family environment are at greater risk for teen dating violence (e.g., Jouriles et al. 2012; Offenhauer and Buchalter 2011). However, the mechanisms through which exposure to family violence and dysfunction contribute to involvement in teen dating violence need to be further elucidated (Temple et al. 2013).
Using a Dynamic Cascade Model of Development to Understand the Etiology of Teen Dating Violence in Alcoholic Families

Early interpersonal experiences are among the most salient developmental influences with potential for long lasting effects (Bretherton 1997). The far-reaching effects of parental psychopathology in early life on adolescent risk for dating violence may be understood within the framework of the dynamic cascade model of development (Dodge et al. 2008; Dodge et al. 2009). According to this model, early life experiences impact developmental outcomes that in turn influence outcomes at subsequent developmental stages. Thus, exposure to adverse social contexts in early childhood can trigger a cascade of negative cognitive, social, and behavioral developmental outcomes across childhood and into adolescence.

The dynamic cascade model can address the complex etiology of teen dating violence by integrating various risk factors into a sequential framework, with each risk factor building upon developmentally earlier factors. At each level of this model, there is the potential for the trajectory to be disrupted or exacerbated depending on individual and/or environmental conditions. An advantage of using such a developmental framework is that it offers multiple time points for intervention. In addition, the model may incorporate multiple theories, with different theories used to explain different pieces of the model.

\section{Developmental pathways to teen dating violence}

Research and theory suggest two pathways through which parental psychopathology in early life can influence the development of aggression and progression to teen dating violence: (a) a marital conflict pathway; and (b) a pathway via parenting behaviors and child self-regulation. Both of these pathways are viewed within the framework of the dynamic cascade model; however, different theories are used to explain each of the hypothesized pathways within this overarching framework. These pathways are depicted in Fig. 1 and elucidated below.

\section{Marital conflict pathway}

Exposure to violence and antisocial behavior in the family of origin is a key risk factor for the development of aggression and teen dating violence (Jouriles et al. 2012; Makin-Byrd and Bierman 2013). According to social learning theory (Bandura 1973, 1977; Ireland and Smith 2009), children learn to behave aggressively through exposure to aggressive models, particularly when they see the model rewarded for the behavior (i.e., maintaining dominance or control over others). Thus, compared with 


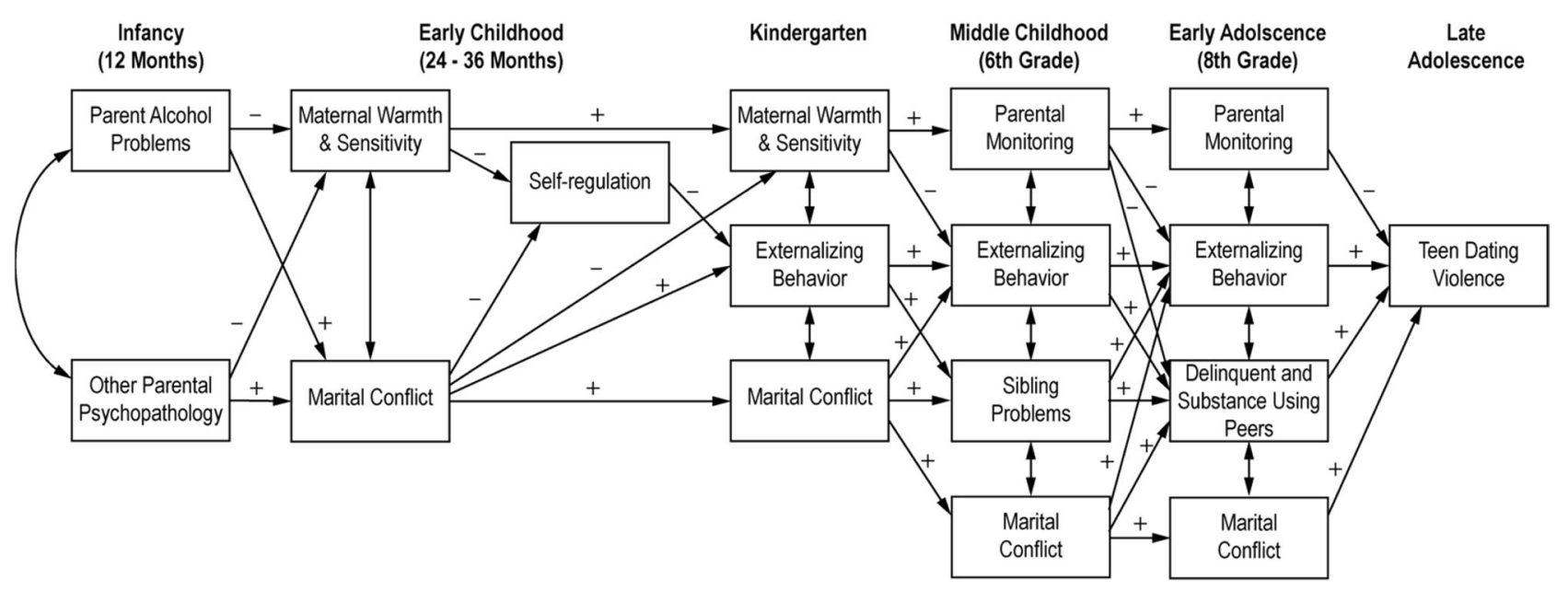

Fig. 1 Conceptual model

non-exposed children, those exposed to interparental or other violence in the home learn to use aggression to deal with conflict, be aggressive in their interpersonal relationships, and/or be more tolerant of aggression directed toward them. Home becomes a "training ground" for practicing and reinforcing aggressive behavior, and it is with families that children first take on and practice the roles of abuser (i.e., with siblings) and/or victim (i.e., with siblings and/or parents; Hoffman and Edwards 2004).

There is a surprising dearth of research on how parents' violence toward each other impacts the sibling relationships of their children. However, there is longitudinal evidence indicating that exposure to family violence in childhood, including both interparental violence and sibling abuse, is associated with children's aggression toward peers and dating partners in adolescence (e.g., Espelage et al. 2014; Narayan et al. 2014). Nevertheless, one limitation of social learning theory in this context is that it fails to address why many youth who are exposed to parental violence do not engage in violence in their interpersonal relationships (Temple et al. 2013). This suggests that there are other mediating or moderating mechanisms driving this relationship (Capaldi and Smith 2003; Cascardi 2016; Maas et al. 2010). Other developmental theories may offer alternative etiological pathways to teen dating violence.

\section{Pathways through parenting behaviors}

In contrast to the direct modeling approach assumed by social learning theory, the ecological/transactional model of development (Cicchetti and Lynch 1993) would argue that the developmental pathways from parenting to involvement in teen dating violence are indirect and transactional, influenced by the dynamic interplay among parent characteristics, child characteristics and environmental forces (i.e., family and school contexts) beginning in infancy. Aggression and self-regulation are child characteristics that begin to emerge early in life, are influenced by parenting behavior, have implications for social functioning and have been linked to dating violence in adolescence (Farley and Kim-Spoon 2014; Maas et al. 2010; Schwartz et al. 2006).

\section{Parenting, self-regulation and externalizing behavior}

A robust body of evidence indicates that the association between parenting and children's externalizing behavior problems, including aggression, is longitudinally mediated by the development of effective self-regulation (Eisenberg et al. 2005). In early childhood, an important aspect of selfregulation involves internalizing rules of conduct to guide behavior. Indeed, this is the ultimate goal of early socialization. Another important aspect of self-regulation that begins to develop later in the first year of life is effortful control, the ability to inhibit a dominant response for a more socially appropriate or rewarding non-dominant response. Effortful control is particularly important for the inhibition of behavioral impulses and regulation of affect. While internalization of rules of conduct is well established before entry into school (Kochanska and Aksan 1995), effortful control continues to exhibit modest developmental change throughout childhood and remains fairly stable into adolescence (Eisenberg et al. 2005; Raffaelli et al. 2005, Steinberg 2014).

Research has highlighted the role of maternal warmth, sensitivity and disciplinary strategies as key predictors of self-regulation (Choe et al. 2013; Eisenberg et al. 2001). Children with warm, sensitive parents are better able to regulate their arousal and focus attention on salient environmental demands. As a result, these children are better able to process parental directives, benefit from parental 
guidance, internalize parental rules and inhibit inappropriate behavior. Parental psychopathology contributes to marital conflict and interferes with parents' abilities to provide guidance in a warm and sensitive manner. Parents who are harsh in their interactions with their children fail to teach children appropriate ways of dealing with frustration and anger, resulting in child dysregulation and externalizing behavior (Chang et al. 2003; Eisenberg et al. 2001). Exposure to parental conflict and harshness can also threaten a young child's sense of security, eliciting a fear response. Over time, fearful arousal can diminish a child's capacity for self-regulation and trigger both internalizing and externalizing symptoms (Davies et al. 2012).

Prior research suggests that aggressive children process social information differently than non-aggressive children and rely more on aggressive strategies for handling conflict (Crick and Dodge 1996; Keltikangas-Järvinen 2001). Parents, especially mothers, help to teach children how to interpret and respond to provocative or ambiguous social stimuli (Chang et al. 2003). In families characterized by psychopathology, conflict and parental harshness, children learn to interpret ambiguous social stimuli as being hostile or threatening, prompting an aggressive response. Indeed, prior research conducted with the current sample revealed that the lack of warmth and sensitivity exhibited toward toddlers by parents in alcoholic families was associated with lower child self-regulation in the preschool years and higher externalizing behavior in kindergarten (Eiden et al. 2007).

\section{Family influences in middle childhood: sibling problems}

In middle childhood, parenting continues to influence child behavior and other social relationships. After parents, children have their first important relationships with siblings. Within sibling relationships children have early opportunities to develop prosocial behaviors such as sharing, empathy, negotiation and conflict resolution, skills which require self-regulation. Parents can facilitate and guide these sibling exchanges, thereby influencing the self-regulatory skills of both children as well as the quality of sibling relationships (Padilla-Walker et al. 2010). It is not surprising, then, that parental harshness and insensitivity are associated with lower quality sibling relationships, and greater bullying and conflict between siblings (Wolke et al. 2015). While parenting influences the quality of sibling relationships, siblings play a role in sustaining or mitigating aggressive behavior toward others because youth often look to siblings, particularly older siblings, for guidance on how to behave with peers (Farley and Kim-Spoon 2014). As a result, youth who have difficult sibling relationships may also have difficulties in relationships with peers. Indeed, research shows that sibling relationships that are characterized by abuse and aggression put youth at greater risk for fighting and bullying among peers (Espelage et al. 2014; Wolke et al. 2015). In contrast, affectionate sibling relationships in middle childhood are predictive of prosocial behaviors, greater self-regulation and fewer externalizing behaviors in early adolescence (Padilla-Walker et al. 2010).

\section{Parental influences in early adolescence}

In middle childhood and early adolescence, youth begin to shift their social focus toward peers. As involvement in independent and peer-related activities increases, parents provide less direct oversight of their children, but provide protective influence through monitoring. Monitoring involves parental awareness of children's activities, whereabouts, and friends (Barnes and Farrell 1992) so that parents can provide the teen with the appropriate limits, guidance, and feedback needed to make good choices. It also requires good parent-child communication and parental support to be effective. Monitoring has been established as one of the most important protective factors in adolescence, reducing risk for a variety of negative outcomes including substance use (Barnes and Farrell 1992; Eiden et al. 2016), on-line harassment (Wolke et al. 2015), early sexual involvement (Maria et al. 2014), gang membership (McDaniel 2012), deviancy and peer aggression (Low and Espelage 2014), affiliation with delinquent peers (Barnes et al. 2006) and dating violence (Foshee et al. 2015, 2016).

\section{Affiliation with deviant peers}

Peer affiliation plays an important role in many adolescent risk behaviors, but the nature of the peer group can be influenced by parenting and parental monitoring (Barnes et al. 2006). Youth with strong parental bonds are less susceptible to negative peer influence, less likely to engage in risky behaviors, and are less likely to be victimized (Jaccard et al. 2005; Maas et al. 2010). In contrast, poor quality parent-child relationships resulting from harsh parenting and marital conflict can contribute to deficits in social skills and self-regulation and high levels of externalizing behaviors (e.g., Eiden et al. 2007; Finger et al. 2010). Children with these characteristics are less likely to be accepted by their peers (Eiden et al. 2007), which in turn may lead them to affiliate with peers who engage in or are accepting of aggressive and delinquent behaviors (Farley and Kim-Spoon 2014; Maas et al. 2010). Affiliation with delinquent peers is one of the most reliable predictors of violence and victimization among adolescents, including teen dating violence and sexual assault (Bandyopadhyay et al. 2010; Dodge et al. 2008). Moreover, associating with delinquent peers tends to restrict the pool of potential dating partners to adolescents who are group members or are more accepting of externalizing and deviant behavior. This may 
account for the high levels of reciprocity of dating violence perpetration and victimization found in many adolescent samples (Farley and Kim-Spoon 2014; Maas et al. 2010).

\section{Current Study}

The theoretical importance of early parenting behaviors on the development of child self-regulation and externalizing behaviors, including aggression, suggests that children growing up in families characterized by parental psychopathology may be at high risk for involvement in teen dating violence. In particular, children of alcoholics (COAs) may be at elevated risk for teen dating violence due to their propensity to engage in externalizing problem behaviors, including aggression (Eiden et al. 2007). While the links between parental problem drinking and early childhood externalizing behaviors are well established, it is unclear whether these parental influences on childhood aggression extend into adolescence and whether they contribute to involvement in dating violence as either a victim or a perpetrator. The purpose of the current study is to examine the role of family processes in the development of aggressive behavior and teen dating violence among a sample of children of alcoholic fathers and control families.

Two pathways from parental psychopathology to teen dating violence were tested within a dynamic cascade model of development that spanned developmental periods from infancy (12 months) to late adolescence: (a) a marital conflict pathway and (b) pathways through parenting (see Fig. 1). Consistent with previous research, we expected parental psychopathology in infancy to be associated with marital conflict in early childhood (Finger et al. 2010) and that marital conflict would remain stable across childhood and adolescence. Based on social learning theory, we expected marital conflict to predict teen dating violence both directly as a result of modeling conflictual behavior and indirectly through its influence on externalizing behavior and through problematic social relationships (i.e., sibling problems in middle childhood and affiliation with deviant peers in early adolescence). Consistent with prior research with this sample in early childhood (e.g., Eiden et al. 2007), we also expected parental psychopathology to impact teen dating violence through its effects on maternal warmth/sensitivity in early childhood, lower self-regulation in early childhood and higher externalizing behavior in kindergarten. We further anticipated that from kindergarten the parenting pathway would lead to three early adolescent proximal predictors of teen dating violence: (a) externalizing behavior present in kindergarten would remain stable across middle childhood and into early adolescence, directly contributing to dating violence in late adolescence; (b) maternal warmth and sensitivity in kindergarten would be positively associated with parental monitoring in middle childhood and early adolescence, which in turn would be inversely associated with externalizing behavior and affiliation with delinquent peers in early adolescence and inversely associated with teen dating violence in late adolescence; and (c) externalizing behaviors in kindergarten would be indirectly associated with teen dating violence through its effect on sibling problems in middle childhood and affiliation with delinquent peers in early adolescence. Finally, we expected that affiliation with delinquent peers in early adolescence would be a proximal predictor of dating violence.

\section{Method}

\section{Participants}

The initial sample consisted of 227 families (116 girls, 111 boys) with 12-month-old infants who were recruited to participate in a longitudinal study of parenting and infant development. Families were classified as being in one of two groups: the nonalcoholic or control group consisting of parents with no or few alcohol problems since the child's birth $(n=102)$ and the father alcoholic group with families in which the father met criteria for alcohol abuse or dependence $(n=125)$. Within the father alcoholic group, 95 mothers were light drinkers or abstainers and 30 mothers were heavy drinkers or had current alcohol problems. Given the low number of mothers who met criteria for problem drinking, and the fact that in the majority of cases where mother was a problem drinker, father was also a problem drinker, classification was made on the basis of father's alcohol status.

The majority of parents in the study were European American (94\% of mothers and $87 \%$ of fathers), approximately $5 \%$ of mothers and $7 \%$ of fathers were African American and 2\% of parents were Hispanic/Latino, Native American, or other. Parental education ranged from less than a high school degree to postgraduate degree, with 59\% of mothers and $54 \%$ of fathers having completed at least some post-high school education. Annual family income ranged from $\$ 4000$ to $\$ 95,000$ at recruitment $(M=\$ 41,824$; $\mathrm{SD}=\$ 19,423)$. All of the mothers and fathers were residing together with the child in the study at recruitment, and $88 \%$ of the parents were married to each other. Mothers' and fathers' ages at recruitment ranged from 19 to 41 years $(M$ $=30.7, \mathrm{SD}=4.5)$ and $21-58$ years $(M=33.0, \mathrm{SD}=5.9)$, respectively.

At the time of the current assessment, the participants were in $11 / 12$ th grade and on average $17.68(\mathrm{SD}=1.89)$ years of age. The majority of the adolescents identified as European American (91.9\%), 2.7\% identified as African American, and $5.4 \%$ as multiracial. Slightly less than $2 \%$ of 
the sample identified as being Hispanic/Latino. Most of the students were in 11 th $(35.1 \%)$ or 12 th grades $(42.5 \%)$, although $18.3 \%$ were enrolled in post high school education (college or trade school) and $2.2 \%$ had dropped out before completing high school.

\section{Procedure}

\section{Recruitment for initial study}

The names and addresses of these families were obtained from the New York State birth records for Erie County (see Eiden et al. 2007, for procedural details). Families meeting basic eligibility criteria were sent an introductory letter. Those who returned the enclosed form indicating interest in the study were screened for eligibility over the telephone. To be eligible, parents had to be primary caregivers and cohabiting since the infant's birth, mothers were between 18 and 40 years old at the time of the child's birth, mothers could not have used drugs during pregnancy or in the past year (except for less than two instances of marijuana use), mothers' average drinking was less than one drink a day during pregnancy and mothers did not drink five or more drinks on a single occasion during pregnancy. During the phone screen, mothers were administered the Family History Research Diagnostic Criteria for alcoholism with regard to their partners' drinking (Andreasen et al. 1986), and fathers were screened with regard to their alcohol use, problems and treatment. Because of the large pool of families potentially eligible for the nonalcoholic group, alcoholic and nonalcoholic families were matched on race/ ethnicity, maternal education, child gender, parity and marital status.

Family lab assessments were conducted at eight different child ages, in infancy and early childhood (12, 18, 24, and 36 months), at kindergarten age (5-6 years of age), in middle childhood (6th grades, about 11-12 years of age), in early adolescence (8th grade, 13-14 years of age) and in later adolescence (11th/12th grades, 15-19 years of age). Mother-child visits were conducted first, followed by fatherchild visits 1 to 2 weeks later. A parental questionnaire assessment was also conducted at 48 months. Assessments took place through parental self-reports and laboratory observations from infancy to early adolescence. Children completed interviews and questionnaires from middle childhood to late adolescence. Each wave of the study was approved by the University at Buffalo Social Science Institutional Review Board. Informed written consents were obtained from both parents, and child assents were obtained from kindergarten-age and older children. Children who had reached their 18th birthday by the late adolescent assessment provided informed consent. Data from infancy (12months), early childhood (24-, 36-months), kindergarten, middle childhood (6th grade), early adolescence (8th grade) and late adolescence were used in the current analyses.

\section{Measures}

Parents' alcohol use

An adapted, self-report measure of The University of Michigan Composite International Diagnostic Interview (Anthony et al. 1994; Kessler et al. 1994) was used to assess parental alcohol abuse and dependence. Questions were reworded to inquire as to "how many times" problems had been experienced, as opposed to whether it happened "very often."

In addition to the screening criteria, Diagnostic and Statistical Manual of Mental Disorders, Fourth Edition (DSM-IV; American Psychiatric Association 2000) criteria for alcohol abuse and dependence diagnoses for current alcohol problems (in the past year) were used to assign final diagnostic group status. For abuse criteria, recurrent alcohol problems were those occurring at least 3-5 times in the past year or 1-2 times in three or more problem areas. Families in which parents met diagnostic criteria on the screener and questionnaire were assigned to the alcoholic group at the first assessment.

\section{Antisocial behavior}

Maternal antisocial behavior was assessed using a modified, 28-item version on the Antisocial Behavior Checklist (Ham et al. 1993; Zucker and Noll 1980) in infancy. The measure was only used at one time point because it is a measure of lifetime antisocial behavior. The internal consistency for the current sample was quite high (Cronbach's $\alpha=.82$ ). The scores were skewed and were transformed using square root transformations.

\section{Parents' depressive symptoms}

The Center for Epidemiological Studies Depression scale (CES-D; Radloff 1977) was used to measure mothers' and fathers' depressive symptoms in infancy. The CES-D is a scale designed to measure depressive symptoms in community populations. It is a widely used, self-report measure with high internal consistency and strong test-retest reliability (Boyd et al. 1982). Internal consistency in the present study ranged from .88 for fathers to .91 for mothers.

\section{Marital conflict}

Mothers and fathers reported on physical and verbal marital aggression measured at each time point from infancy to early adolescence. Physical aggression was measured using 
the Conflict Tactics Scale (CTS; Straus 1979). In the current study, the items focusing on moderate (e.g., push, grab, or shove) to severe (e.g., hit with fist) physical aggression, but not the very severe items (e.g., burnt or scalded, use of weapons), were included. Parents' reported frequency of their own and their partners' physical aggression toward each other over the past 12 months on a seven-item scale ranging from 0 "0 times" to 6 " 20 or more times." Due to under-reporting of aggressive behaviors, especially by men (Archer 2002), indicators of each variable were created by taking the maximum of the mother and father reports $(\alpha$ $=.82-.86$ ).

\section{Maternal warmth and sensitivity}

During the 24- and 36-month assessments, mothers were asked to interact with their child as they normally would at home for $10 \mathrm{~min}$ in a room full of toys. These free-play interactions were coded using a collection of global fivepoint rating scales using the Parent-Child Early Relational Assessment (Clark 1999). These scales have been validated for mother-child interactions ranging from child ages of two months to 5 years. A composite measure of maternal warmth/sensitivity at each assessment point was derived from these scales. The warmth/sensitivity composite included items such as expressed positive affect, positive involvement, responsiveness, reading child cues, flexibility, low intrusiveness, consistency/predictability, and low negative affect, with higher scores indicating more positive behavior. The internal consistency (Cronbach's alpha) for this scale was .93 .

At kindergarten, mothers decorated a picture frame with their child for $20 \mathrm{~min}$. This interaction was coded using the Iowa Family Interaction Rating Scales (Melby et al. 1998). These rating scales were designed to measure both verbal and non-verbal behaviors as well as affective aspects of the interactions along nine-point rating scales. The warmth/ sensitivity composite at kindergarten age included items such as positive reinforcement, sensitive child centered behaviors, humor, positive mood, warmth-support, prosocial behaviors, and physical affection. The internal consistency for this composite scale was Cronbach's $\alpha=.94$.

Two sets of coders blind to group membership scored the mother-child interactions. Coders were trained on both scales until they achieved at least $80 \%$ reliability, with observations selected at random for inter-rater reliability checks. For the 24 month assessments, interrater reliability was calculated for $17 \%$ of the sample $(n=38)$ and the intraclass correlation coefficient was .81 . For the 36 month assessment, interrater reliability was calculated for $(15 \%)$ of the interactions $(n=28)$ and the intra-class correlation coefficient was .96 . Inter-rater reliability was calculated for $12 \%$ of the sample at kindergarten age, and was .90 .

\section{Self-regulation}

Self-regulation was assessed in early (36 months) childhood. The self-regulation measure at 36 months included an effortful control battery, an observational measure of internalization of maternal rules and an observational measure of internalization of fathers' rules. The effortful control battery consisted of a battery of three tasks developed by Kochanska et al. (1996) and Kochanska and Knaack (2003): a snack delay, whisper, and lab gift (see Eiden et al. 2007; Kochanska et al. 1996 for details). The scores on all three tasks were standardized and a final effortful control score was computed by taking the average of all the scores. The internal consistency of this scale at 3 years was Cronbach's $\alpha=.79$.

Observations of child internalization were conducted with the paradigm developed by Kochanska and her colleagues (Kochanska and Aksan 1995; Kochanska et al. 1996). Children's internalization of the parental directive to not touch the objects on a prohibited shelf was assessed during a $12 \mathrm{~min}$ observational paradigm (Kochanska and Aksan 1995). The child's behavior was coded for every 15-s interval averaged across the entire $12 \mathrm{~min}$ so that high scores reflected high behavioral internalization. Internalization was coded by two independent coders blind to group status and other information about the families. Interrater reliability based on 20 cases (640 15-s coded segments) was $\kappa=.98$. The percent agreement for the categories ranged from $90 \%$ for gentle touch to $100 \%$ for deviation. These three indicators (observations of internalization of mother's rules, internalization of father's rules and effortful control battery) were significantly correlated with each other. Thus, a composite variable was computed by standardizing the measures and taking the average of the two internalization variables and summing with the effortful control composite. The internal consistency of this scale was Cronbach's alpha $=.77$.

\section{Child externalizing behavior}

Child externalizing problem behaviors were assessed using the Externalizing subscale of the Child Behavior Checklist (CBCL; Achenbach 1991). Maternal reports of externalizing problem behaviors were used in the model at kindergarten age and youth self-reports (YSR) were used in middle childhood and early adolescent assessments. The CBCL is a widely used measure of children's internalizing and externalizing behaviors and has well-established psychometric properties. The Externalizing subscale contains items relating to attentional difficulties, delinquency, physical aggression, noncompliance, and oppositional behavior, rated on three-point response scale ranging from 0 "not true" to 2 "very true." Higher scores indicate higher levels of 
externalizing problem behaviors. The internal consistency for maternal report at kindergarten age was Cronbach's $\alpha$ $=.86$, YSR middle childhood was $\alpha=.89$ and early adolescence was $\alpha=.92$.

\section{Parental monitoring}

Parental monitoring was measured with a nine-item child report scale that assessed the degree to which mothers were aware of the child's whereabouts, acquaintances, and behaviors (Grundy et al. 2007; Sturge-Apple et al. 2003) at the middle childhood and early adolescent assessments. Sample items included "how often does your mom/dad know where you go when you are not at home?" and "how often does your mom/dad know who your friends are?" Children answered each item using a 5-point Likert-type response scale that ranged from 0 (never) to 4 (always). Items were scored such that higher scores indicated greater knowledge. Internal consistencies ranged from Cronbach's $\alpha=.79$ at 6 th grade to .84 at 8 th grade. Maternal and paternal monitoring scores were significantly correlated at both middle childhood $(r=.42, p<.001)$ and early adolescence $(r=.61, p<.001)$, and were composited by taking the average of maternal and paternal reports within each age. High scores on these two final measures reflected high parental monitoring.

\section{Sibling problems}

Maternal report of child's sibling problems was measured in middle childhood (6th grade) using the sibling problems subscale of The Social Adjustment Inventory for Children and Adolescents (SAICA; John et al. 1987). The sibling problems subscale consisted of six items (e.g., injures siblings, is injured by siblings) with items rated on a four-point response scale ranging from 1 "not at all a problem" to 4 "severe problem." The internal consistency for the current sample was $\alpha=.78$.

\section{Peer delinquency and substance use}

Peer delinquency was assessed by child report at 8th grade using a modified, 11 item version of the Peer Delinquency Scale (Loeber et al. 1991). The measure was modified to reflect the child's peer group. Children were asked to identify their peer group and then complete the delinquency scale with regard to these peers. Children were asked to report the number of friends who had engaged in delinquent behavior such as skipping school without an excuse, going joyriding, and hitting someone with the idea of hurting that person in the last six months. These items were rated on a five-point scale ranging from $0=$ None to $4=$ All. The internal consistency for the current sample was $\alpha=.82$.
Peer substance use was assessed through child report at 8th grade using a 10 item scale that measured how many of the adolescents' peers used alcohol, cigarettes, marijuana, and other drugs on an occasional or regular basis based on previous studies (Chassin et al. 1996), with response options ranging from $0=$ None to $4=$ All. The internal consistency for the current sample was $\alpha=.84$. Given that the peer delinquency and peer substance use measures were highly correlated, $r=.70$, these measures were then averaged to create a composite peer delinquency and substance use measure.

\section{Involvement in teen dating violence}

The Conflict in Adolescent Dating Relationships Inventory (CADRI; Wolfe et al. 2001), a self-report questionnaire assessing multiple forms of abusive behavior (physical, sexual, threatening, relational and emotional/ verbal) that may occur between dating adolescents, was used to measure teen relationship conflict. Adolescents reported on their own and their partners' behaviors by indicating how often certain behaviors occurred within the context of their current or most recent romantic relationship. Items were rated on a four-point scale ranging from 1 "never" to 4 "often." Scores for victimization and perpetration were combined because they were highly correlated $(r=.91)$, suggesting a high degree of mutual involvement in dating violence. The internal consistency of this scale was $\alpha=.94$.

\section{Results}

\section{Missing Data}

As would be expected of any longitudinal study involving multiple family members, there were incomplete data for some participants at one or more of the five assessment points included in this study. Of the 227 families included in analyses, all provided data at 12 and 18 months; 222 (97.8\%) mothers provided data at 24 months; 205 (90.3\%) mothers provided data at 36 months; $185(81.5 \%)$ mothers provided data at kindergarten, $165(72.7 \%)$ mothers and 164 $(72.2 \%)$ children provided data at 6th grade, $154(67.8 \%)$ mothers and $162(71.4 \%)$ children provided data at 8 th grade and $184(81.1 \%)$ children provided data at 12 th grade. Of the children who provided data at 12th grade, 144 (77.4\%) had been, or were currently, in a relationship and could provide valid data on teen dating violence.

There were no group differences between families with missing vs. complete data on any of the alcohol variables, depressive symptoms or parenting. There were also no differences between the two groups of families (complete vs. missing data) on any of the child outcome variables. 
However, families with missing data had mothers who reported higher antisocial behavior compared with those with complete data $(M \mathrm{~s}=39.25$ and $41.96, S D \mathrm{~s}=8.54$ and 10.01, respectively). Although it is clear that the data were not missing completely at random because of group differences on maternal antisocial behavior, data did meet criteria for being missing at random (MAR; Little and Rubin 1989). Full-information maximum likelihood (FIML) estimation procedures were used with this final sample to estimate parameters (Arbuckle 1996). This missing data approach includes all cases in the analysis, even those with missing data. FIML produces more accurate estimates of population parameters than would be obtained using listwise deletion.

\section{Data Analytic Plan}

First, the means, standard deviations and inter-correlations among the study variables were examined. Next, in order to examine the hypotheses of the current study, structural equation modeling (SEM) was used to test the conceptual model depicted in Fig. 1. All SEM analyses were conducted using Mplus (Version 7.11; Muthén and Muthén 1998-2013). Standardized parameter estimates using FIML are presented. The goodness of fit of the models was examined by using the comparative fit index (CFI) and the root mean square error of approximation (RMSEA). The CFI varies between 0 and 1 , and values of .95 or higher indicate good fit (Hu and Bentler 1995). The RMSEA is bounded by 0 and will take on that value when a model exactly reproduces a set of observed data. A value of .05 to .06 is indicative of close fit, a value of .08 is indicative of marginal fit, and higher values are indicative of poor fit (Browne and Cudeck 1993). Given the limits of sample size, we were unable to test if the full etiological model differed by gender. However, we did control for gender in the overall model, given that boys tend to exhibit more aggressive behaviors than girls in this sample (Edwards et al. 2006).

\section{Descriptive and Correlational Analyses}

The prevalence of each type of dating violence by perpetration and victimization as measured by the CADRI is presented in Table 1. Consistent with findings in larger samples (e.g., Wolfe et al. 2001), emotional (psychological) abuse was the most frequently reported form of dating violence. Given the relatively low rates of other types of dating aggression in this sample, scores were summed to create a total teen dating violence score.

The alcohol and control groups were compared to determine if they differed on any of the variables included in the model. Several significant differences were observed
Table 1 Prevalence rates of dating violence subscales

\begin{tabular}{llllll}
\hline Type of aggression & \multicolumn{2}{l}{ Perpetration } & & \multicolumn{2}{c}{ Victimization } \\
\cline { 2 - 3 } & $N$ & & & $N$ & $\%$ \\
\hline Physical & 7 & 4.8 & & 11 & 7.5 \\
Threatening & 5 & 3.4 & & 6.2 \\
Sexual & 11 & 7.5 & & 12 & 8.2 \\
Relational & 3 & 2.1 & 7 & 4.8 \\
Emotional & 83 & 58.5 & & 87 & 60.8 \\
\hline
\end{tabular}

(see Table 2). The marital conflict and delinquent peer affiliation variables were square root transformed given the skewness of the data. First, lifetime maternal antisocial behaviors and parental depressive symptoms in infancy were higher in the alcoholic compared to non-alcoholic group. Second, alcoholic families reported higher levels of marital conflict in infancy and early childhood, with a trend toward higher conflict in kindergarten as well. Third, mothers in alcoholic families displayed lower warmth/sensitivity during play interactions with their toddlers and preschoolers compared to the control group mothers. Fourth, adolescents in alcoholic families were significantly more likely to affiliate with delinquent and substance using peers than were those in control families. There were no group differences on sibling problems or on teen dating violence.

Correlations of the study variables with each other are shown in Table 3. Results indicated that there was modest stability in maternal warmth from 24 months to kindergarten, child externalizing behaviors from kindergarten to early adolescence, marital conflict from 24 months to early adolescence and in parental monitoring from middle childhood to early adolescence. Teen dating violence was positively associated with maternal depressive symptoms at 12 months, sibling problems in middle childhood, and externalizing behaviors and affiliation with deviant peers in early adolescence. Dating violence was inversely associated with maternal warmth and sensitivity at 36 months and parental monitoring in early adolescence. The bivariate associations of all other variables with teen dating violence were not significant; however, they were included in the model because they were theoretically relevant and correlated with other mediational variables in the model.

\section{Pathways from Parental Psychopathology in Infancy to Teen Dating Violence}

The model examined the influence of parental psychopathology in infancy on child externalizing behavior and involvement in teen dating violence in late adolescence via a parenting pathway and a marital conflict pathway. The 
Table 2 Comparisons of study variables by 12 month alcohol group

\begin{tabular}{|c|c|c|c|}
\hline Variable & $\begin{array}{l}\text { Control } \\
\text { group }\end{array}$ & $\begin{array}{l}\text { Father alcoholic } \\
\text { group }\end{array}$ & $t$ value \\
\hline \multicolumn{4}{|l|}{ Infancy (12 months) } \\
\hline $\begin{array}{l}\text { Maternal depressive } \\
\text { symptoms }\end{array}$ & $7.11(6.18)$ & $9.67(8.03)$ & $2.66 * *$ \\
\hline $\begin{array}{l}\text { Paternal depressive } \\
\text { symptoms }\end{array}$ & $6.41(6.26)$ & $8.79(7.46)$ & $2.54 *$ \\
\hline $\begin{array}{l}\text { Maternal anti-social } \\
\text { behavior }\end{array}$ & $34.28(4.44)$ & $37.46(5.95)$ & $4.43 * * *$ \\
\hline Marital conflict & $-.23(.79)$ & $.25(.93)$ & $3.13 * *$ \\
\hline \multicolumn{4}{|c|}{ Pre-School (24-36 months) } \\
\hline $\begin{array}{l}\text { Maternal warmth } \\
\text { (24 months) }\end{array}$ & $4.70(.44)$ & $4.38(.53)$ & $4.87 * * *$ \\
\hline $\begin{array}{l}\text { Maternal warmth } \\
\text { (36 months) }\end{array}$ & $6.47(1.54)$ & $6.01(1.52)$ & $2.13 *$ \\
\hline $\begin{array}{l}\text { Child self-regulation } \\
\text { (36 months) }\end{array}$ & $10.02(.68)$ & $9.97(.77)$ & .41 \\
\hline $\begin{array}{l}\text { Marital conflict } \\
\text { (36 months) }\end{array}$ & $.60(1.07)$ & $1.50(1.67)$ & $4.60 * * *$ \\
\hline \multicolumn{4}{|c|}{ Early childhood (Kindergarten) } \\
\hline Maternal warmth & $6.01(.89)$ & $6.03(1.12)$ & .10 \\
\hline $\begin{array}{l}\text { Child externalizing } \\
\text { behavior (CBCL) }\end{array}$ & $7.76(5.09)$ & $8.92(5.38)$ & 1.50 \\
\hline Marital conflict & $.62(1.00)$ & $.92(1.23)$ & $1.81^{\mathrm{t}}$ \\
\hline \multicolumn{4}{|c|}{ Middle childhood (6th grade) } \\
\hline Parental monitoring & $3.28(.52)$ & $3.17(.49)$ & 1.40 \\
\hline $\begin{array}{l}\text { Child externalizing } \\
\text { behavior (CBCL) }\end{array}$ & $5.35(4.39)$ & $6.58(5.13)$ & 1.65 \\
\hline Marital conflict & $.41(.84)$ & $.65(1.20)$ & 1.53 \\
\hline Child sibling problems & $7.98(2.63)$ & $8.62(2.76)$ & 1.22 \\
\hline \multicolumn{4}{|c|}{ Early adolescence (8th grade) } \\
\hline Parental monitoring & $3.19(.53)$ & $3.04(.67)$ & 1.51 \\
\hline $\begin{array}{l}\text { Child externalizing } \\
\text { behavior (YSR) }\end{array}$ & $6.98(5.27)$ & $8.68(6.07)$ & $1.85^{\mathrm{t}}$ \\
\hline $\begin{array}{l}\text { Delinquent peer } \\
\text { affiliation }\end{array}$ & $-.19(.85)$ & $.13(.91)$ & $2.29 *$ \\
\hline Marital conflict & $-.28(.72)$ & $.48(.80)$ & 1.63 \\
\hline \multicolumn{4}{|c|}{ Late adolescence (8th grade) } \\
\hline Teen dating violence & $3.71(4.96)$ & $3.90(4.57)$ & .24 \\
\hline
\end{tabular}

$C B C L$ child behavior checklist, $Y S R$ youth self-report

${ }^{\mathrm{t}} p<.10 ; * p<.05 ; * * p<.01 ; * * * p<.001$

model included causal paths from alcohol group status, mothers' antisocial behavior, maternal and paternal depressive symptoms and child gender as exogenous variables to maternal warmth and sensitivity and marital conflict in the toddler years (24 months). From maternal warmth and sensitivity in toddler years, direct paths estimating the stability of parenting behavior (i.e., maternal warmth and sensitivity from 24 months to kindergarten, maternal monitoring in 6th and 8th grade) predicting dating violence were examined. Lagged paths from parenting to externalizing behavior in childhood and early adolescence also were examined. An indirect pathway from maternal warmth and sensitivity at 24 months, to self-regulation at 36 months and externalizing behavior in kindergarten, $6^{\text {th }}$ and $8^{\text {th }}$ grades, with paths estimating stability of child externalizing behavior from early childhood to adolescence and lagged paths from externalizing behaviors to sibling problems in middle childhood and peer delinquency in early adolescence were also examined. Finally, the model included lagged paths from marital conflict at 24 months to child externalizing behavior across childhood and adolescence and stability paths in marital conflict. In addition to these causal paths, the model included covariances among variables measured within each time point. Child gender was included as a covariate.

Results indicated that this conceptual model fit the data adequately, with the exception of CFI which was marginally acceptable, $\chi^{2}(149)=227.42, \quad p<.01 ; \quad R M S E A=.048$ [.035-.060]; $C F I=.89$. Given the less than adequate CFI, we examined the modification indices (MI), which indicated that the addition of two theoretically justified pathways would substantially improve the fit of the model (MIs > 10): a path from alcohol group status to marital conflict at 36 months and a path from self-regulation at 36 months to externalizing behavior in sixth grade. The addition of these two pathways significantly improved the fit of the model, $\Delta \chi^{2}(2)=17.67, p<.001$, and resulted in a final model that fit the data well, $\chi^{2}(147)=209.75, p<.01 ; R M S E A=.043$ [.03-.06]; $C F I=.913$. The final model explained about $16 \%$ of the variance in teen dating violence and is presented in Fig. 2. For ease of presentation, only the significant pathways and covariances are depicted with solid lines.

\section{Pathways via marital conflict}

Marital conflict has been identified as a risk factor for teen dating violence involvement, although few studies have examined prospective prediction from early childhood. In this study, parental psychopathology in infancy was associated with higher marital conflict in the toddler years, and families with alcohol problems in infancy reported higher marital conflict in the preschool years. Marital conflict was stable from 24 months to 8th grade; however, contrary to predictions, 8th grade marital conflict was not a proximal predictor of teen dating violence. Rather, the model indicated that there was an indirect relationship between marital conflict and teen dating violence via child externalizing behavior, such that marital conflict at 36 months predicted kindergarten externalizing behavior. Externalizing behavior remained stable across childhood and into early adolescence; 8th grade externalizing behavior directly predicted dating violence in late adolescence. There was also a 


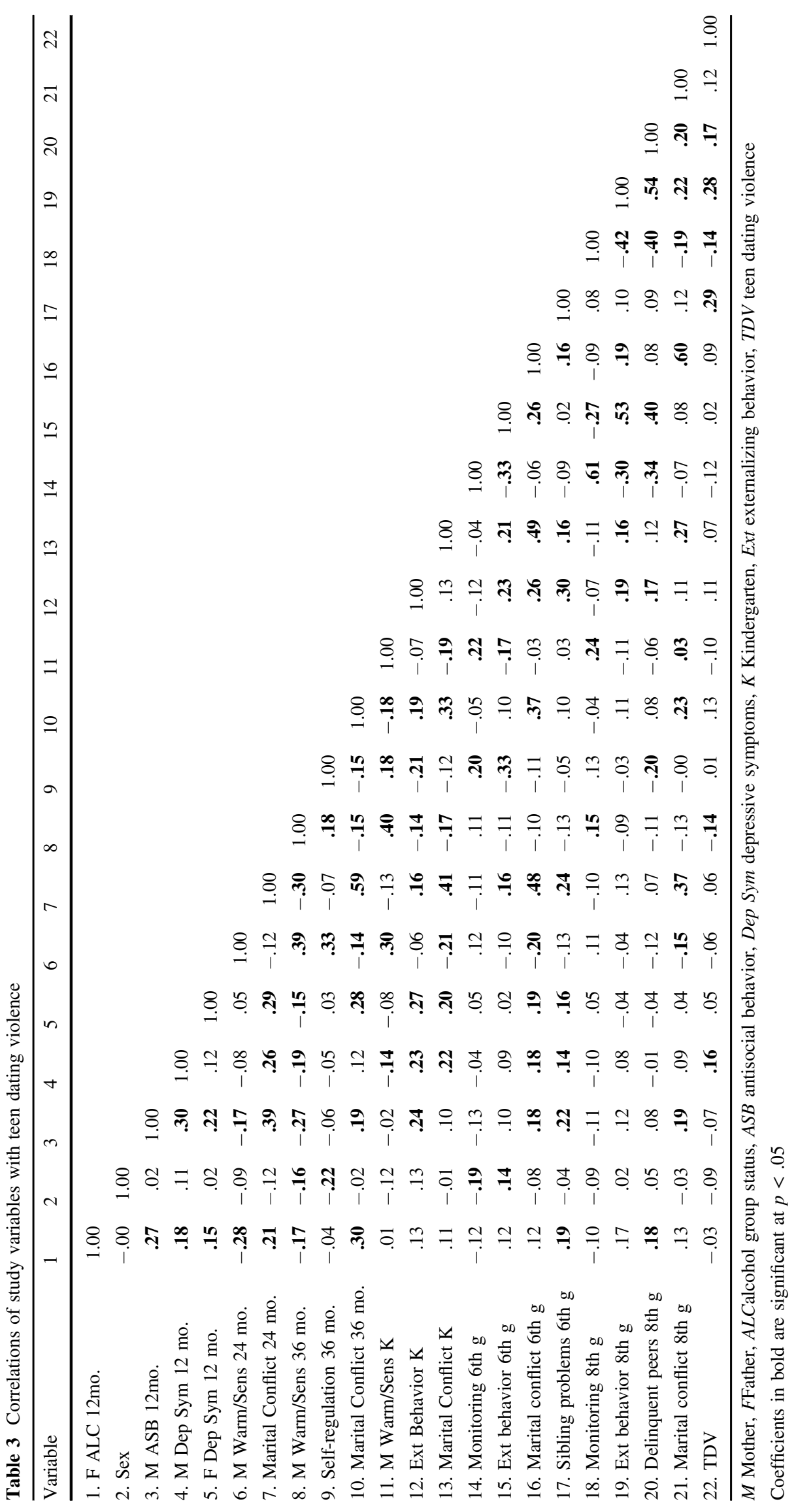




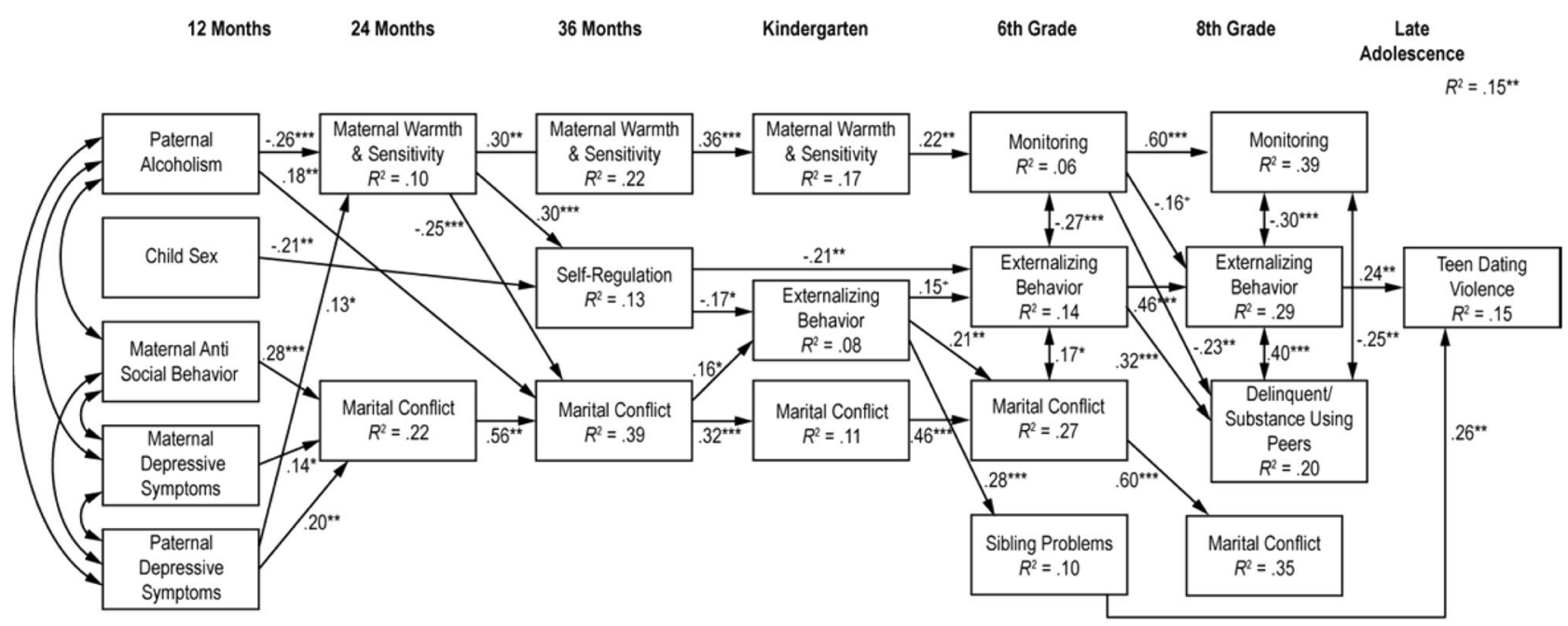

Fig. 2 Etiological model of TDV. Sex $0=$ girls, $1=$ boys. $+p<.07$, * $p<.05$, ** $p<.01$, ***p $p<.001$

within-time association between marital conflict and externalizing behavior at 6th grade, indicating that the prospective, transactional associations between these variables remained even after accounting for the other predictors in the model and the within time associations.

\section{Pathways via parenting behavior}

Consistent with previous findings using the current data set, alcohol group status in infancy was associated with lower maternal warmth and sensitivity toward toddlers at 24 months. Maternal warmth and sensitivity was stable from 24 months through kindergarten and was positively associated with monitoring in 6th and 8th grade. Monitoring was not directly associated with teen dating violence. However, there was an indirect influence of monitoring on teen dating violence via externalizing behavior. That is, higher monitoring was associated with lower externalizing behavior both within time and prospectively from 6th grade to 8th grade. Externalizing behavior was stable from 6th to 8th grade and 8th grade externalizing behavior was a proximal predictor of involvement in dating violence in late adolescence.

The model also supported a second pathway from maternal warmth and sensitivity in the toddler years to involvement in dating violence in late adolescence via selfregulation in the preschool years (36 months). Children with warm and sensitive mothers in the toddler years had higher self-regulation at preschool age, which in turn prospectively predicted lower externalizing behavior in kindergarten. The inclusion of the path from preschool self-regulation to 6th grade externalizing behavior somewhat weakened the stability of externalizing behavior from kindergarten to 6th grade which was originally significant, indicating greater changes in externalizing as a function of high selfregulation at preschool age. This suggests that selfregulatory skills developed in preschool continue to exert a protective influence on behavior into middle childhood.

\section{Externalizing behavior predicts difficulties in social relationships}

The model supported the hypothesis that externalizing behavior exhibited at one time point would prospectively predict problems in significant social relationships at subsequent time points. That is, as predicted, externalizing behavior in kindergarten was associated with 6th grade sibling problems, externalizing behavior in 6th grade predicted affiliation with delinquent and substance using peers in 8th grade and externalizing behavior in 8th grade predicted teen dating violence in late adolescence. Contrary to expectations, sibling problems in 6th grade did not predict affiliation with delinquent peers in 8th grade, and affiliation with delinquent peers was not predictive of involvement in teen dating violence. However, experiencing sibling problems in middle childhood was predictive of involvement in dating violence in late adolescence.

\section{Discussion}

There has long been recognition that family processes in early life play an important role in the development of teen dating violence, with several researchers calling for longitudinal, theory-based research to identify the etiological roots of dating violence (e.g., National Institute of Justice 2011; Schwartz et al. 2006; Shorey et al. 2008). Until recently, research into the etiology of teen dating violence 
has been hampered by the dearth of longitudinal data that extends back into early childhood and considers the family context. The current study addresses this gap in the literature by examining the etiological pathways to teen dating violence beginning in infancy with a sample at high risk due to parental psychopathology related to fathers' alcohol problems.

The results of this study add to a growing body of developmental research indicating that teen dating violence has its roots in childhood externalizing behavior and that parents play an important role in the development and maintenance of such behavior (e.g., Madan Morris et al. 2015; Makin-Byrd and Bierman 2013). It further elucidates the complex and varied developmental pathways through which this occurs. The current study is unique in that it identifies family and child risk and protective factors associated with teen dating violence that are present as early as 12 months of age. The study also addresses how these early risk and protective factors are related to previously identified risk factors present in early adolescence, thus providing a lifespan developmental picture of teen dating violence risk within the framework of a dynamic cascade model. In this study, parental psychopathology in infancy (i.e., alcohol problems, antisocial behavior, depressive symptoms) was associated with a family context characterized by marital conflict and low maternal warmth and sensitivity. These conditions ultimately contributed to the child's involvement in teen dating violence through facilitating and maintaining childhood externalizing behaviors, including aggression. Although both childhood and adolescent aggression have long been subjects of developmental research, to our knowledge, this is one of the first longitudinal studies to prospectively link risk factors for the development of childhood externalizing behavior to involvement in teen dating violence in late adolescence, beginning with parental risk factors present in infancy. The advantage of such a multi-stage etiological model is that is that it can reveal pathways and opportunities for prevention and intervention at key developmental periods.

Within the framework of a dynamic cascade model of development, two pathways from parental psychopathology in infancy to involvement in dating violence in late adolescence were examined: (a) a marital conflict pathway informed by social learning theory (Bandura 1973) and (b) a pathway through parenting, informed by the ecological transactional model of development (Cicchetti and Lynch 1993). As anticipated, parental psychopathology had adverse effects on both the quality of the marital relationship and parenting in early childhood, setting the stage for each of the hypothesized pathways.

Social learning theory is frequently used to explain the relationship between violence in the family of origin and involvement in teen dating violence. Based on social learning theory, we hypothesized that adolescents growing up in households characterized by marital conflict would learn to use aggression to manage relationship conflict and thus would be more likely to be involved in teen dating violence. We also anticipated that exposure to marital conflict would be associated with difficulties in other social relationships including sibling problems in middle childhood and affiliation with delinquent peers in early adolescence. Contrary to expectations, marital conflict was not directly associated with sibling problems, affiliation with delinquent peers or teen dating violence at any time point in the model. However, there was an indirect effect of marital conflict on teen dating violence via externalizing behavior. Children growing up in households characterized by marital conflict in early childhood were more likely to exhibit externalizing behavior in kindergarten. Externalizing behavior remained stable across childhood and adolescence, and contributed to teen dating violence both directly and indirectly through sibling problems in middle childhood. The lack of a direct relationship between marital conflict at any time point and teen dating violence in late adolescence suggests that involvement in dating violence as a victim or a perpetrator cannot be explained through simple modeling effects. This finding points to the need to consider potential mediating mechanisms.

There was support for an etiological pathway from parental psychopathology in infancy to teen dating violence in late adolescence via parenting behavior. Specifically, the model highlighted the role of maternal warmth and sensitivity in early childhood as protective against involvement in teen dating violence through its influences on child selfregulation in early childhood and parental monitoring in middle childhood and early adolescence. Both selfregulation and parental monitoring are protective against externalizing behavior, a key risk factor for teen dating violence.

Parents who are warm and sensitive are better able to teach their children appropriate ways of processing and dealing with emotions so that they are less likely to act out in a hostile or disruptive manner (Chang et al. 2003, Eisenberg et al. 2001). In contrast, harsh and aggressive parenting can lead to maladaptive and externalizing behaviors (Schwartz et al. 2006). In this sample, parental psychopathology in infancy was associated with reduced maternal warmth and sensitivity in the toddler years, which in turn was associated with poor child self-regulation at 36 months and higher externalizing behavior in kindergarten. The current study extended previous findings (e.g., Eiden et al. 2007) by examining the pathways from parenting and self-regulation in early childhood into middle childhood and adolescence.

The results indicated that self-regulation in preschool continued to exert a direct influence on externalizing 
behavior into middle childhood, above and beyond kindergarten externalizing behavior, underscoring the importance of early childhood self-regulation on subsequent developmental outcomes. Adolescents who are better able to self-regulate are more likely to have high quality romantic relationships characterized by caring, support, low-negativity, and mutual satisfaction with the relationship (Farley and Kim-Spoon 2014). Theoretically, the ability to dampen a pre-potent response would be relevant to handling conflict within the context of a dating relationship, where the dominant response to feeling angry, hurt or emotionally threatened may be to lash out physically or verbally against a partner. Individuals high in effortful control may be better able to suppress these strong aggressive urges in favor of more appropriate responses that improve the quality of the relationship.

Warm and sensitive parenting in early childhood was also associated stronger parental monitoring in middle childhood and adolescence. Parental monitoring has been reliably identified as protective against a number of adolescent risk behaviors, including teen dating violence (Foshee et al. 2015, 2016). The findings from the current study provide some insight into how parental monitoring protects against teen dating violence. Adolescents who are well monitored by their parents are less likely to be involved in externalizing behaviors, and externalizing behavior is a strong and proximal predictor of involvement in dating violence. Parental monitoring was inversely associated with externalizing behavior both prospectively from middle childhood to early adolescence and within time at early adolescence. Parental monitoring was also negatively associated with affiliation with delinquent peersanother risk factor for externalizing behavior-both prospectively and within time in early adolescence.

Externalizing behavior in early adolescence was the strongest and most direct predictor of teen dating violence. Consistent with the ecological transactional model of development, child externalizing behavior was strongly influenced by parental characteristics and the family context in early childhood (i.e., parental psychopathology, marital conflict and harsh/insensitive parenting) and in turn influenced how the child interacted with his/her social environment at subsequent developmental time points. Interestingly, there was a transactional relationship between marital conflict and kindergarten externalizing behavior, with marital conflict at 36 months predicting child's externalizing behavior in kindergarten, which in turn predicted both sibling problems and parent marital conflict in 6th grade. This suggests that middle childhood may be a critical period for preventing dating violence through family intervention, as it appears that child externalizing behavior in middle childhood contributes to family conflict above and beyond the influence of prior marital conflict. As children near the end of childhood, they shift their social focus toward peers, yet they rely on what they have learned in the family to guide their behavior with peers (PadillaWalker et al. 2010). In a stressful family context characterized by conflictual interactions among parents and siblings, children are unlikely to learn the social skills they need to successfully navigate adolescent social relationships with peers and dating partners, thereby setting the stage for teen dating violence.

Affiliation with delinquent peers is often cited as a risk factor for teen dating violence (e.g., Bandyopadhyay et al. 2010; Madan Morris et al. 2015). As indicated above, adolescents who lack self-regulatory skills and engage in externalizing behavior are likely to experience peer rejection. This leads them to affiliate with other undercontrolled peers, who may be accepting of aggression and involved in delinquent activities including substance use. During adolescence, it is likely that romantic partners will be selected from among this peer group or a group with similar values (Capaldi and Smith 2003). If both members of the dyad are low in self-regulation and high in aggression, relationships will likely be of lower quality and characterized by conflict. This may explain the high levels of mutual aggression found within violent adolescent dating relationships in the current sample and in others (e.g., Capaldi and Smith 2003; Chiodo et al. 2012). Contrary to expectations, affiliation with delinquent peers in early adolescence was not predictive of teen dating violence in late adolescence in this sample. The reason for this is unclear. It may be because most of the dating violence reported in the current sample involved emotional abuse rather than physical or sexual abuse. Approximately $60 \%$ of the participants reported involvement in emotional abuse perpetrated toward or by an intimate partner, whereas less than $10 \%$ reported involvement in physical, threatening, or sexual abuse. Unfortunately, such high rates of emotional abuse may be considered normative and thus, not necessarily limited to expression in delinquent populations. It may be that delinquent peer affiliation is related more strongly to involvement in more deviant or severe forms of dating violence, such as physical or sexual abuse. Due to the small sample size, we were unable to examine pathways to different types of dating aggression.

\section{Implications for the Prevention of Teen Dating Violence}

The findings from this study clearly indicate that risk for involvement in teen dating violenceis not restricted to early adolescence. Rather, it stems from a lifetime of externalizing behavior and social difficulties. The dynamic cascade model of risk development examined in this study reveals several critical points for intervention that could help to reduce adolescent involvement in teen dating violence, even 
before adolescence. Ideally, intervention should occur in families when children are very young. Children reared in homes characterized by parental psychopathology, including parental alcoholism, are at increased risk of involvement in dating violence through the adverse effects of psychopathology on parenting behaviors that thwart the development of self-regulatory skills needed to inhibit aggression and control behavior. The role of maternal parenting behavior in the context of risk posed by fathers' alcohol problems may be especially critical and high maternal warmth and sensitivity may be protective against child externalizing behavior. Interventions designed to promote maternal warmth and sensitivity in the toddler years may be particularly helpful for reducing externalizing through improving parent-child relations and facilitating the development of self-regulation.

Middle childhood also appears to be a critical period for intervention. Externalizing behavior in kindergarten appears to contribute to family conflict (i.e., between parents and with siblings) in middle childhood, a time when youth are beginning to form close relationships with individuals outside of the family unit. Presumably, as youth begin to move into these new social realms, they carry with them the interpersonal skills and conflict tactics learned in the family. Pediatricians can screen for family violence, including sibling and marital conflict, and help connect families with resources to promote communication, conflict management and self-regulatory skills. Schools can also provide interventions to improve social skills and conflict resolution. Programs that promote social and emotional learning may be particularly promising for reducing violence and delinquency (i.e., externalizing behaviors) among middle school students and early adolescents (Jagers et al. 2015). Older adolescents in high school may also benefit from such interventions; however, more research is needed to confirm this (Williamson et al. 2015).

\section{Limitations and Strengths}

As with any study, there are limitations that need to be considered in interpreting the results. First, the sample consisted of predominantly White families. Different developmental pathways or processes may occur in families of other races/ethnicities. Most significantly, the relatively small sample size prohibited us from testing a fully comprehensive model that included other variables that should be theoretically associated with involvement in teen dating violence (e.g., social competency, parent-to-child aggression, attachment). In developing the model, we chose the pathways and time points that were most theoretically meaningful from the standpoint of an ecological/transactional model of development. Preliminary analysis determined that some of the theoretically related constructs (e.g., social competency) did not have predictive power within the proposed models, so they were dropped from the final model to conserve power. We were also restricted by sample size in examining if the pathways to teen dating violence varied for boys and girls or for same sex relationships. These relationships should be explored in larger, more representative samples.

Strengths of the study include an excellent retention rate, measurement of different aspects of family functioning and the use of multiple methods and measures including laboratory assessments, as well as observational, parent report and adolescent report data collected at key transition points in development (toddler to preschool years, entry into school, shift from middle to high school). The study contributes to the current literature on teen dating violence by highlighting the importance of parenting in early childhood and its implications for the development of aggression and self-regulation across childhood and into adolescence.

\section{Conclusion}

Although teen dating violence is typically seen as a problem specific to adolescent development, the findings of this study indicate that risk for dating violence starts much earlier in life. Parental psychopathology (i.e., alcohol problems, antisocial behavior, depressive symptoms) occurring in infancy sets the stage for involvement in teen dating violence by creating a hostile and conflictual family environment that contributes to and maintains externalizing behaviors from early childhood into early adolescence. Fortunately, this risk can also be mitigated via positive parenting behaviors. Warm and sensitive parenting during the child's toddler years appears to protect against externalizing behavior through reduced marital conflict and increased child self-regulation in preschool as well as stronger parental monitoring in middle childhood and early adolescence. The findings point to the need for early intervention with children and families at risk due parental psychopathology. Preschool and middle childhood may be especially critical periods for intervention. Improving family relationships in early life may serve to better prepare youth to navigate the social complexities and stressors of peer and dating relationships in adolescence, thereby reducing risk of teen dating violence.

Acknowledgements We would like to thank Jillian Fish, Shahirah Gillespie, Marlana Howard, and Toni Torchia for their assistance with the late adolescent wave of data collection. We would also like to thank the anonymous reviewers for their feedback on earlier versions of this manuscript.

Authors' Contributions J.A.L. and R.D.E. conceived of the study, participated in its design and implementation, and drafted the 
manuscript; R.D.E. and J.L. conducted the statistical analyses, M.C. participated in the coordination of the study and performed the measurement, J.H. contributed to the statistical analysis and interpretation of the data, and K.E.L. was involved in the design of the study and interpretation of the data. All authors contributed to drafts of the manuscript and have read and approved the final manuscript.

Funding This research was supported by Award 2012-W9-BX0001, awarded by the National Institute of Justice, Office of Justice Programs, U.S. Department of Justice and by the National Institute of Alcoholism and Alcohol Abuse of the National Institutes of Health R01 AA010042 and R21AA021617. The opinions, findings and conclusions or recommendations expressed in this exhibition are those of the authors and do not necessarily reflect those of the Department of Justice or the National Institutes of Health.

Compliance with Ethical Standards All procedures in this study were conducted in compliance with the ethical standards outlined by the University at Buffalo Institutional Review Board and Federal Policy for the Protection of Human Subjects (Common Rule).

Conflict of Interest The authors declare that they have no competing interests.

Ethical Approval The procedures for all waves of this study were approved by the University at Buffalo Social and Behavioral Sciences Review Board. Individual informed consent and assent was obtained from all participants in this study.

Informed Consent Informed written consents were obtained from both parents as teach wave of data collection, and child assents were obtained from kindergarten-age and older children. Children who had reached their 18th birthday by the late adolescent assessment provided informed consent.

\section{References}

Achenbach, T. M. (1991). Manual for the child behavior checklist/418 and 1991 profile. Burlington, VT: University of Vermont Department of Psychiatry.

American Psychiatric Association. (2000). Diagnostic and statistical manual of mental disorders. 4th edn. Washington, DC: Author.

Andreasen, N. C., Rice, J., Endicott, J., Reich, T., \& Coryell, W. (1986). The family history approach to diagnosis: How useful is it? Archives of General Psychiatry, 43, 421-429.

Anthony, J. C., Warner, L. A., \& Kessler, R. C. (1994). Comparative epidemiology of dependence on tobacco, alcohol, controlled substances, and inhalants: Basic findings from the national comorbidity survey. Experimental and Clinical Psychopharmacology, 2, 244-268.

Arbuckle, J. L. (1996). Full information estimation in the presence of incomplete data. In G. A. Marcoulides \& R. E. Schumacker (Eds.), Advanced structural equation modeling: Issues and techniques (pp. 243-277). Mahwah, NJ: Lawrence Erlbaum Associates.

Archer, J. (2002). Sex differences in physically aggressive acts between heterosexual partners: A meta-analytic review. Aggression and Violent Behavior, 7, 313-351.

Bandura, A. (1973). Aggression: A social learning analysis. Englewood Cliffs, NJ: Prentice-Hall, Inc.

Bandura, A. (1977). Social learning theory. Upper Saddle River, NJ: Prentice Hall.
Bandyopadhyay, A., Deokar, A., \& Omar, H. A. (2010). Adolescent dating violence: A comprehensive review. International Journal of Child and Adolescent Health, 3, 305-320.

Barnes, G. M., \& Farrell, M. P. (1992). Parental support and control as predictors of adolescent drinking, delinquency, and related problem behaviors. Journal of Marriage and the Family, 54, 763-776.

Barnes, G. M., Hoffman, J. H., Welte, J. W., Farrell, M. P., \& Dintcheff, B. A. (2006). Effects of parental monitoring and peer deviance on dubstance use and delinquency. Journal of Marriage and Family, 68(4), 1084-1104.

Boyd, J. H., Weissman, M. M., Thompson, W. D., \& Myers, J. K. (1982). Screening for depression in a community sample: Understanding the discrepancies between depression syndrome and diagnostic scales. Archives of General Psychiatry, 39, 1195-1200.

Bretherton, I. (1997). Bowlby's legacy to developmental psychology. Child Psychiatry and Human Development, 28(1), 33-43. doi:10. 1023/A:1025193002462.

Browne, M. W., \& Cudeck, R. (1993). Alternative ways of assessing model fit. In K. A. Bollen \& J. S. Long (Eds.), Testing structural equation models (pp. 136-162). Newbury Park, CA: Sage.

Capaldi, D. M., \& Smith, D. G. (2003). The development of aggression in young male/female couples. In P. Florsheim (Ed.), Adolescent romantic relations and sexual behavior (pp. 243-278). Mahwah, NJ: Lawrence Erlbaum Associates. Reprinted from: Not in File.

Cascardi, M. (2016). From violence in the home to physical dating violence victimization: The mediating role of psychological distress in a prospective study of female adolescents. Journal of Youth and Adolescence, 45(4), 777-792. doi:10.1007/s10964016-0434-1.

Chang, L., Schwartz, D., Dodge, K. A., \& McBride-Chang, C. (2003). Harsh parenting in relation to child emotion regulation and aggression. Journal of Family Psychology, 17(4), 598-606. doi:10.1037/0893-3200.17.4.598.

Chassin, L., Curran, P. J., Hussong, A. M., \& Colder, C. R. (1996). The relation of parent alcoholism to adolescent substance use: A longitudinal follow-up study. Journal of Abnormal Psychology, 105(1), 70-80.

Chiodo, D., Crooks, C. V., Wolfe, D. A., McIsaac, C., Hughes, R., \& Jaffe, P. G. (2012). Longitudinal prediction and concurrent functioning of adolescent girls demonstrating various profiles of dating violence and victimization. Prevention Science, 13(4), 350-359. doi:10.1007/s11121-011-0236-3.

Choe, D. E., Olson, S. L., \& Sameroff, A. J. (2013). Effects of early maternal distress and parenting on the development of children's self-regulation and externalizing behavior. Development and Psychopathology, 25(2), 437-453. doi:10.1017/ S0954579412001162.

Cicchetti, D., \& Lynch, M. (1993). Toward an ecological/transactional model of community violence and child maltreatment: Consequences for children's development. Psychiatry, 56(1), 96-118.

Clark, R. (1999). The parent-child early relational assessment: A factorial validity study. Educational and Psychological Measurement, 59, 821-846.

Crick, N. R., \& Dodge, K. A. (1996). Social information-processing mechanisms on reactive and proactive aggression. Child Development, 67(3), 993-1002. doi:10.2307/1131875.

Davies, P. T., Ciccetti, D., \& Martin, M. J. (2012). Toward greater specificity in identifying associations among interparental aggression, child emotional reactivity to conflict and child problems. Child Development, 83, 1789-1804.

Dodge, K. A., Greenberg, M. T., \& Malone, P. S. (2008). Testing an idealized dynamic cascade model of the development of serious 
violence in adolescence. Child Development, 79(6), 1907-1927. doi:10.1111/j.1467-8624.2008.01233.x.

Dodge, K. A., Malone, P. S., Lansford, J. E., Miller, S., Pettit, G. S., \& Bates, J. E. (2009). A dynamic cascade model of the development of substance use onset. Boston, MA: Wiley-Blackwell.

Edwards, E. P., Eiden, R. D., Colder, C. R., \& Leonard, K. E. (2006). The development of aggression in 18 to 48 month old children of alcoholic parents. Journal of Abnormal Child Psychology, 34, 409-423.

Eiden, R. D., Chavez, F., \& Leonard, K. E. (1999). Parent-infant interactions among families with alcoholic fathers. Development and Psychopathology, 11(4), 745-762. doi:10.1017/ S0954579499002308.

Eiden, R. D., Edwards, E. P., \& Leonard, K. E. (2007). A conceptual model for the development of externalizing behavior problems among kindergarten children of alcoholic families: Role of parenting and children's self-regulation. Developmental Psychology, 43, 1187-1201.

Eiden, R. D., \& Leonard, K. E. (2000). Paternal alcoholism, parental psychopathology, and aggravation with infants. Journal of Substance Abuse, 11(1), 17-29.

Eiden, R. D., Lessard, J., Colder, C. R., Livingston, J., Casey, M., \& Leonard, K. E. (2016). Developmental cascade model for adolescent substance use from infancy to late adolescence. Developmental Psychology, 52(10), 1619-1633. doi:10.1037/ dev0000199.

Eisenberg, N., Gershoff, E. T., Fabes, R. A., Shepard, S. A., Cumberland, A. J., Losoya, S. H., \& Murphy, B. C. (2001). Mother's emotional expressivity and children's behavior problems and social competence: Mediation through children's regulation. Developmental Psychology, 37(4), 475-490. doi:10.1037/00121649.37.4.475.

Eisenberg, N., Zhou, Q., Spinrad, T. L., Valiente, C., Fabes, R. A., \& Liew, J. (2005). Relations among positive parenting, children's effortful control, and externalizing problems: A three-wave longitudinal study. Child Development, 76(5), 1055-1071. doi:10.1111/j.1467-8624.2005.00897.x.

Espelage, D. L., Low, S., Rao, M. A., Hong, J. S., \& Little, T. D. (2014). Family violence, bullying, fighting, and substance use among adolescents: A longitudinal mediational model. Journal of Research on Adolescence, 24(2), 337-349.

Exner-Cortens, D., Eckenrode, J., \& Rothman, E. (2013). Longitudinal associations between teen dating violence victimization and adverse health outcomes. Pediatrics, 131(1), 71-78.

Farley, J. P., \& Kim-Spoon, J. (2014). The development of adolescent self-regulation: Reviewing the role of parent, peer, friend, and romantic relationships. Journal of Adolescence, 37(4), 433-440. doi:10.1016/j.adolescence.2014.03.009.

Finger, B., Eiden, R. D., Edwards, E. P., Leonard, K. E., \& Kachadourian, L. (2010). Marital aggression and child peer competence: A comparison of three conceptual models. Personal Relationships, 17(3), 357-376.

Finger, B., Kachadourian, L. K., Molnar, D. S., Eiden, R. D., Edwards, E. P., \& Leonard, K. E. (2010). Alcoholism, associated risk factors, and harsh parenting among fathers: Examining the role of marital aggression. Addictive Behaviors, 35(6), 541-548.

Foshee, V. A., McNaughton Reyes, H. L., Chen, M. S., Ennett, S. T., Basile, K. C., DeGue, S., \& Bowling, J. M. (2016). Shared risk factors for the perpetration of physical dating violence, bullying, and sexual harassment among adolescents exposed to domestic violence. Journal of Youth and Adolescence, 45(4), 672-686. doi:10.1007/s10964-015-0404-z.

Foshee, V. A., McNaughton Reyes, L., Tharp, A. T., Chang, L.-Y., Ennett, S. T., Simon, T. R., \& Suchindran, C. (2015). Shared longitudinal predictors of physical peer and dating violence.
Journal of Adolescent Health, 56(1), 106-112. doi:10.1016/j.ja dohealth.2014.08.003.

Fuller, B. E., Chermack, S. T., Cruise, K. A., Kirsch, E., Fitzgerald, H. E., \& Zucker, R. A. (2003). Predictors of aggression across three generations among sons of alcoholics: Relationships involving grandparental and parental alcoholism, child aggression, marital aggression and parenting practices. Journal of Studies on Alcohol, 64(4), 472-483.

Grundy, A. M., Gondoli, D. M., \& Blodgett Salafia, E. H. (2007). Marital conflict and preadolescentbehavioral competence: Maternal knowledge as a longitudinal mediator. Journal of Family Psychology, 21(4), 675-682. doi:10.1037/0893-3200.21. 4.675 .

Ham, H. P., Zucker, R. A., \& Fitzgerald, H. E. (1993). Assessing antisociality with the antisocial behavior checklist: Reliability and validity studies. Poster presented at the annual meeting of the American Psychological Society, Chicago.

Hoffman, K. L., \& Edwards, J. N. (2004). An integrated theoretical model of sibling violence and abuse. Journal of Family Violence, 19(3), 185-200. doi:10.1023/B:JOFV.0000028078.71745.a2.

Hu, L. T., \& Bentler, P. M. (1995). Evaluating model fit. In R. H. Hoyle (Ed.), Structural equation modeling: Concepts, issues, and applications (pp. 76-99). Thousand Oaks, CA: Sage.

Hutchinson, D. M., Mattick, R. P., Braunstein, D., Malonely, E., \& Wilson, J. (2014). The impact of alcohol use disorders on family life: A review of the empirical literature. Retrieved from Sydney, New South Wales. https://ndarc.med.unsw.edu.au/resource/ impact-alcohol-use-disorders-family-life-review-empiricalliterature

Ireland, T. O., \& Smith, C. A. (2009). Living in partner-violent families: Developmental links to antisocial behavior and relationship violence. Journal of Youth and Adolescence, 38(3), 323-339. doi:10.1007/s10964-008-9347-y.

Jaccard, J., Blanton, H., \& Dodge, T. (2005). Peer influences on risk behavior: An analysis of the effects of a close friend. Developmental Psychology, 41(1), 135-147. doi:10.1037/0012-1649.41. 1.135 .

Jagers, R. J., Harris, A., \& Skoog, A. (2015). A review of classroombased SEL programs at the middle school level. In J. A. Durlak, C. E. Domitrovich, R. P. Weissberg \& T. P. Gullotta (Ed.), Handbook of social and emotional learning. New York, NY: Guilford Press.

John, K., Gammon, G., Prusoff, B., \& Warner, V. (1987). The social adjustment inventory for children and adolescents (SAICA): Testing of a new semi-structured interview. Journal of the American Academy of Child and Adolescent Psychiatry, 26, 898-911.

Jouriles, E. N., Mueller, V., Rosenfield, D., McDonald, R., \& Dodson, M. C. (2012). Teens' experiences of harsh parenting and exposure to severe intimate partner violence: Adding insult to injury in predicting teen dating violence. Psychology of Violence, 2(2), 125-138.

Keltikangas-Järvinen, L. (2001). Aggressive behaviour and social problem-solving strategies: A review of the findings of a seven-year follow-up from childhood to late adolescence. Criminal Behaviour and Mental Health, 11(4), 236-250. doi:10.1002/cbm.398.

Kessler, R. C., McGonagle, K. A., Zhao, S., Nelson, C. B., Hughes, M., Eshleman, S., Wiltchen, H. E., \& Kendler, K. S. (1994). Lifetime and 12-month prevalence of DSM-III-R psychiatric disorders in the United States: Results from the national comorbidity survey. Archives of General Psychiatry, 51, 8-19.

Kochanska, G., \& Aksan, N. (1995). Mother-child mutually positive affect, the quality of child Compliance to requests and prohibitions, and maternal control as correlates of early internalization. Child Development, 66, 236-254. 
Kochanska, G., \& Knaack, A. (2003). Effortful control as a personality characteristic of young children: Antecedents, correlates, and consequences. Journal of Personality, 71(6), 1087-1112.

Kochanska, G., Murray, K. T., Jacques, T. Y., Koenig, A. L., \& Vandegeest, K. A. (1996). Inhibitory control in young children and its role in emerging internalization. Child Development, 67, 490-507.

Little, R. J. A., \& Rubin, D. B. (1989). The analysis of social science data with missing values. Sociological Methods and Research, 18, 292-326.

Loeber, R., Stouthamer-Loeber, M., Van Kammen, W., \& Farrington, D. P. (1991). Initiation, escalation and desistance in juvenile offending and their correlates. The Journal of Criminal Law \& Criminology, 82, 36-82.

Loukas, A., Fitzgerald, H. E., Zucker, R. A., \& von Eye, A. (2001). Parental alcoholism and co-occurring antisocial behavior: Prospective relationships to externalizing behavior problems in their young sons. Journal of Abnormal Child Psychology, 29(2), 91-106. doi:10.1023/A:1005281011838.

Low, S., \& Espelage, D. (2014). Conduits from community violence exposure to peer aggression and victimization: Contributions of parental monitoring, impulsivity, and deviancy. Journal of Counseling Psychology, 61(2), 221-231. doi:10.1037/a0035207.

Maas, C. D., Fleming, C. B., Herrenkohl, T. I., \& Catalano, R. F. (2010). Childhood predictors of teen dating violence victimization. Violence and Victims, 25, 131-149.

Madan Morris, A., Mrug, S., \& Windle, M. (2015). From family violence to dating violence: Testing a dual pathway model. Journal of Youth \& Adolescence, 44(9), 1819-1835. doi:10.1007/ s10964-105-0328-7.

Makin-Byrd, K., \& Bierman, K. L. (2013). Individual and family predictors of the perpetration of dating violence and victimization in late adolescence. Journal of Youth and Adolescence, 42(4), $536-550$

Maria, D. S., Markham, C., Swank, P., Baumler, E., McCurdy, S., \& Tortolero, S. (2014). Does parental monitoring moderate the relation between parent-child communication and pre-coital sexual behaviours among urban, minority early adolescents? Sex Education, 14(3), 286-298. doi:10.1080/14681811.2014. 886034.

McDaniel, D. D. (2012). Risk and protective factors associated with gang affiliation among high-risk youth: A public health approach. Injury Prevention, 18(4), 253-258. doi:10.1136/injuryprev-2011040083

Melby, J., Conger, R., Book, R., Rueter, M., Lucy, L., Repinski, D., \& Mutchler, L. (1998). The Iowa family interaction rating scales. Ames: Iowa State University, Institute for Social and Behavioral Research.

Muthén, L. K., \& Muthén, B. O. (1998). Mplus user's guide. 7th edn Los Angeles, CA: Muthén \& Muthén. -2013.

Narayan, A. J., Englund, M. M., Carlson, E. A., \& Egeland, B. (2014). Adolescent conflict as a developmental process in the prospective pathway from exposure to interparental violence to dating violence. Journal of Abnormal Child Psychology. doi:10.1007/ s10802-013-9782-4.

National Institute of Justice (2011). Longitudinal data on teen dating violence: Meeting summary. http://www.nij.gov/nij/topics/crime/ intimate-partner-violence/teen-dating-violence/longitudinal-datameeting/welcome.htm, http://www.nij.gov/nij/topics/crime/ intimate-partner-violence/teen-dating-violence/research-agenda. htm.

Offenhauer, P., \& Buchalter, A. (2011). Teen dating violence: A literature review and annotated bibilography. Retrieved from Washington, DC: https://www.ncjrs.gov/pdffiles1/nij/grants/ 235368.pdf.
Padilla-Walker, L. M., Harper, J. M., \& Jensen, A. C. (2010). Selfregulation as a mediator between sibling relationship quality and early adolescents' positive and negative outcomes. Journal of Family Psychology, 24(4), 419-428. doi:10.1037/a0020387.

Radloff, L. S. (1977). The CES-D scale: A self-report depression scale for research in the general population. Applied Psychological Measurement, 1, 385-394.

Raffaelli, M., Crockett, L. J., \& Shen, Y.-L. (2005). Developmental stability and change in self-regulation from childhood to adolescence. The Journal of Genetic Psychology, 166, 54-75.

Schwartz, J. P., Hage, S. M., Bush, I., \& Burns, L. K. (2006). Unhealthy parenting and potential mediators as contributing factors to future intimate violence: A review of the literature. Trauma, violence \& abuse, 7(3), 206-221. doi:10.1177/ 1524838006288932.

Shorey, R. C., Cornelius, T. L., \& Bell, K. M. (2008). A critical review of theoretical frameworks for dating violence: Comparing the dating and marital fields. Aggression and Violent Behavior, 13(3), 185-194.

Smith, P. H., White, J. W., \& Holland, L. J. (2003). A longitudinal perspective on dating violence among adolescent and college-age women. American Journal of Public Health, 93(7), 1104-1109.

Steinberg, L. (2014). Age of opportunity: New lessons from the science of adolescence. New York, NY: Houghton Mifflin Harcourt.

Straus, M. A. (1979). Measuring intra family conflict and violence: The conflict tactics (CT) scales. Journal of Marriage \& the Family, 41, 75-88.

Sturge-Apple, M. L., Gondoli, D. M., Bonds, D. D., \& Salem, L. N. (2003). Mothers' responsive parenting practices and psychological experience of parenting as mediators of the relation between marital conflict and mother-peadolescent relational negativity. Parenting, 3(4), 327-355. doi:10.1207/s15327922par0304_3.

Temple, J. R., Shorey, R. C., Tortolero, S. R., Wolfe, D. A., \& Stuart, G. L. (2013). Importance of gender and attitudes about violence in the relationship between exposure to interparental violence and the perpetration of teen dating violence. Child Abuse \& Neglect, 37(5), 343-352.

Villafuerte, S., Heitzeg, M. M., Foley, S., Yau, W. Y. W., Majczenko, K., Zubieta, J. K., \& Burmeister, M. (2012). Impulsiveness and insula activation during reward anticipation are associated with genetic variants in GABRA2 in a family sample enriched for alcoholism. Molecular Psychiatry, 17(5), 511-519. doi:10.1038/ mp.2011.33.

Williamson, A. A., Modecki, K. L., \& Guerra, N. G. (2015). SEL programs in high school. In J. A. Durlak, C. E. Domitrovich, R. P. Weissberg \& T. P. Gullotta (Eds.), Handbood of social and emotional learning. New York, NY: Guildford.

Wolfe, D. A., Scott, K., Reitzel-Jaffe, D., Wekerle, C., Grasley, C., \& Straatman, A.-L. (2001). Development and validation of the conflict in adolescent dating relationships inventory. Psychological Assessment, 13, 277-293.

Wolke, D., Tippett, N., \& Dantchev, S. (2015). Bullying in the family: Sibling bullying. The Lancet Psychiatry, 2(10), 917-929. doi:10. 1016/S2215-0366(15)00262-X.

Zucker, R. A., \& Noll, R. B. (1980). The antisocial behavior checklist. East Lansing, MI: Department of Psychology, Michigan State University. Unpublished Instrument.

Jennifer A. Livingston, Ph.D is a Senior Research Scientist at the University at Buffalo's Research Institute on Addictions. Her research focuses on the intersection of violence and substance use among adolescents and on the implications of victimization for adolescent health and development. She also studies the links among substance 
use, sexual risk behavior and sexual assault in adolescent and young adult samples.

Rina Das Eiden, Ph.D is a Senior Research Scientist at the Research Institute on Addictions, University at Buffalo, SUNY. Her research examines the impact of parental prenatal and postnatal substance abuse on developmental trajectories of risk and resilience from infancy to adolescence. She is also interested in the prevention of risky trajectories among children at high risk due to parental substance use.

Jared Lessard, Ph.D is a Senior Research and Planning Analyst at Saddleback College. His research interests include adolescence and health psychology.

Meghan Casey, Ed.M is a Project Coordinator and Coding Supervisor at the Research Institute on Addictions. She is interested in developmental assessment and coding of parent-child interactions.

James Henrie, Ph.D is a Social Scientist at the Food and Drug Administration's Center for Tobacco Products. Dr. Henrie's research generally focuses on behaviors and psychosocial factors which impact health outcomes. Currently, his specific interests include of novel tobacco products, especially among adolescents, college students, and those interested in quitting conventional cigarette use.

Kenneth E. Leonard, Ph.D is the Director and Senior Research Scientist of the Research Institute on Addictions at the University at Buffalo, SUNY. His research interests focus on marital/family processes, parenting and infant development, interpersonal aggression, bar violence, and domestic violence. 